\title{
p53 Regulation of the IGF-1/AKT/mTOR Pathways and the Endosomal Compartment
}

\author{
Zhaohui Feng \\ Department of Radiation Oncology, Cancer Institute of New Jersey, University of Medicine and Dentistry \\ of New Jersey, New Brunswick, New Jersey 08903 \\ Correspondence: fengzh@umdnj.edu
}

In response to various stress signals, which introduce infidelity into the processes of cell growth and division, p53 initiates cell-cycle arrest, apoptosis, or senescence to maintain fidelity throughout the cell cycle. Although these functions are traditionally thought of as the major functions of the p53 protein for tumor suppression, recent studies have revealed some additional novel functions of the p53 pathway. These include the down-regulation of two central cell-growth pathways, the IGF/AKT-1 and mTOR pathways, and the upregulation of the activities of the endosomal compartment. The IGF-1/AKT and mTOR pathways are two evolutionarily conserved pathways that play critical roles in regulation of cell proliferation, survival, and energy metabolism. In response to stress, p53 transcribes a group of critical negative regulators in these two pathways, including IGF-BP3, PTEN, TSC2, AMPK $\beta 1$, and Sestrin1/2, which leads to the reduction in the activities of these two pathways. Furthermore, p53 transcribes several critical genes regulating the endosomal compartment, including TSAP6, Chmp4C, Caveolin-1, and DRAM, and increases exosome secretion, the rate of endosomal removal of growth factor receptors (e.g., EGFR) from cell surface, and enhances autophagy. These activities all function to slow down cell growth and division, conserve and recycle cellular resources, communicate with adjacent cells and dendritic cells of the immune system, and inform other tissues of the stress signals. This coordinated regulation of IGF-1/AKT/mTOR pathways and the endosomal compartment by the p53 pathway integrates the molecular, cellular, and systemic levels of activities and prevents the accumulations of errors in response to stress and restores cellular homeostasis after stress.

\section{THE mTOR PATHWAY}

Cell growth and proliferation require environmental signals showing the availability of adequate glucose and amino acids, as well as growth factors as signals for cell proliferation and division. The IGF-1(insulin-like growth
factor-1)/AKT and mTOR (the mammalian target of rapamycin) pathways are two evolutionarily conserved pathways that transmit cell growth and survival signals in cells. They sense the availability of nutrients and growth factors in the environment and respond by signaling for cell growth and division.

Editors: Arnold J. Levine and David Lane

Additional Perspectives on The p53 Family available at www.cshperspectives.org

Copyright (C) 2010 Cold Spring Harbor Laboratory Press; all rights reserved; doi: 10.1101/cshperspect.a001057

Cite this article as Cold Spring Harb Perspect Biol 2010;2:a001057 
Z. Feng

The mTOR is a conserved Ser/Thr kinase, belonging to the phosphatidylinositol kinaserelated (PIKK) family (Fingar and Blenis 2004; Hay and Sonenberg 2004; Inoki et al. 2005; Wullschleger et al. 2006). mTOR forms two complexes in cells, mTOR complex 1 (mTORC1) and mTOR complex 2 (mTORC2). The mTORC1 is composed of mTOR, Raptor, and mLST8 proteins, which is sensitive to rapamycin inhibition (Hara et al. 2002; Kim et al. 2002; Kim et al. 2003). The mTORC2 is composed of mTOR, Rictor, Sin1, and mLST1, which is insensitive to rapamycin inhibition (Jacinto et al. 2004; Sarbassov et al. 2004; Sarbassov et al. 2005a; Jacinto et al. 2006). mTORC1 and mTORC2 have distinctive physical structures and physiological functions. It appears that whereas the mTORC2 complex is involved in cytoskeleton reorganization and cell survival, an important function of the mTORC1 complex is to regulate cell growth and energy metabolism (Fig. 1). The mTOR pathway responds to various signals, including nutrients (glucose and amino acids), energy (ATP and AMP), hypoxia, and growth factors (via IGF-1/AKT pathway). LKB1 and AMPK (AMP-activated protein kinase) are two main upstream kinases of the mTOR pathway that monitor the levels of nutrients and ATP. As a sensor of energy, AMPK is activated by direct binding of AMP resulting from the ATP depletion and increased AMP/ATP ratio in cells that are limiting for glucose or other substrates (Inoki et al. 2003b; Hardie 2005). LKB1 can phosphorylate AMPK and activate AMPK in conjunction with AMP (Yoo et al. 2002; Shaw et al. 2004a; Shaw et al. 2004b; Hardie 2005).

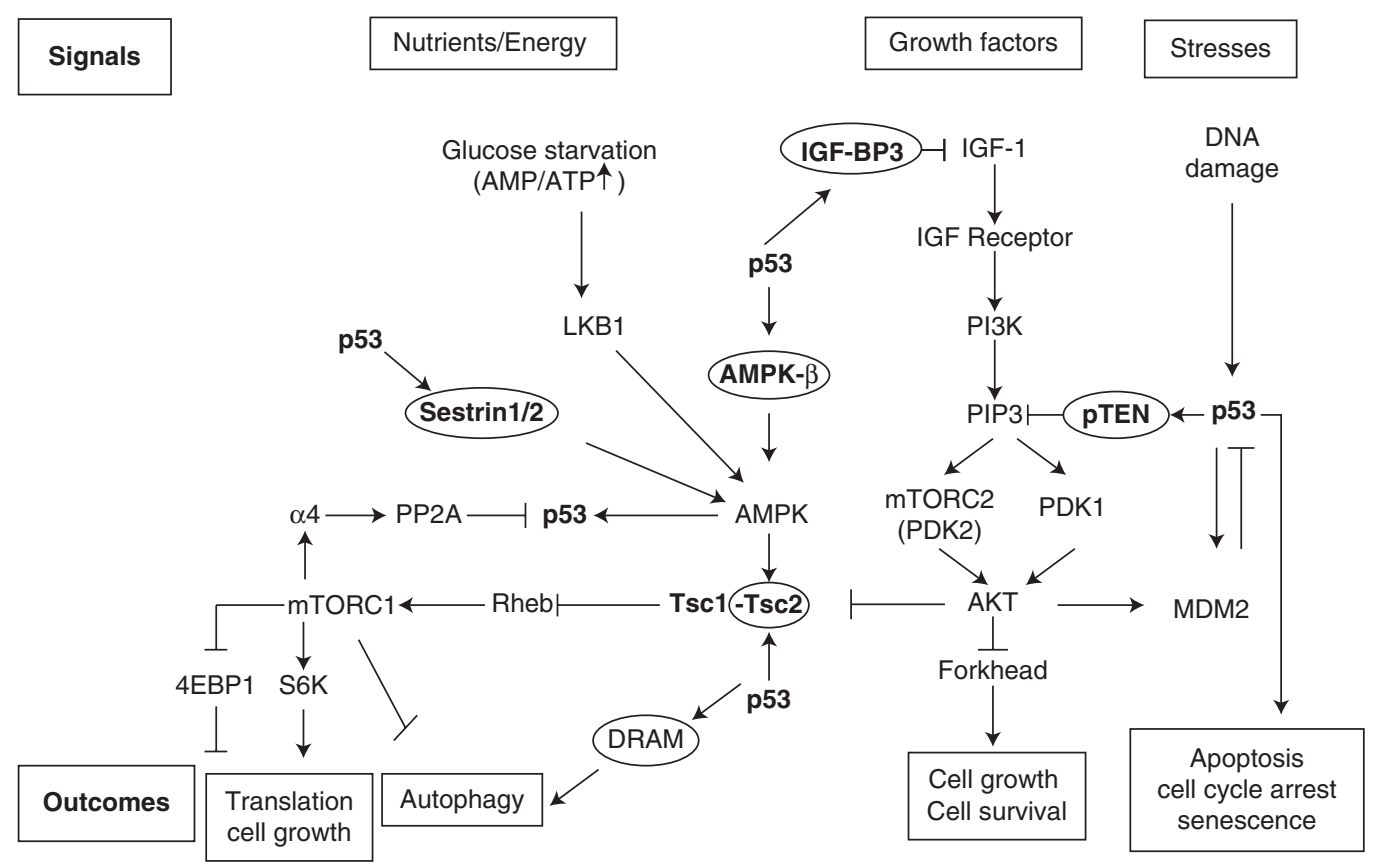

Figure 1. The interconnections between $\mathrm{p} 53$ and IGF-1/AKT/mTOR pathways. p53 negatively regulates IGF-1/ AKT and mTOR pathways through its up-regulation of IGF-BP3, PTEN, TSC2, AMPK $\beta 1$, and Sestrin $1 / 2$ in response to stress. mTORC1 activates the $\alpha-4$ subunit of the PP2A phosphatase to dephosphorylate p53 on Ser15 to inactivate p53, whereas AMPK phosphorylates p53 on Ser15 to activate p53. AKT-MDM2-p53 forms a negative feedback loop to negatively regulate $\mathrm{p} 53$, whereas $\mathrm{p} 53-\mathrm{PTEN}-\mathrm{AKT}-\mathrm{MDM} 2$ forms a positive loop to positively regulate p53. Furthermore, p53 activates autophagy through its regulation of mTOR pathway and DRAM. This extensive communication and coordination between p53 and IGF-1/AKT/mTOR pathways slows down cell growth and division to prevent the accumulations of errors in response to stress and restores cellular homeostasis after stress is resolved. 
Activated AMPK then phosphorylates and activates the TSC2 protein (Inoki et al. 2003b), which forms a protein complex with TSC1. Both TSC1 and TSC2 are tumor suppressor genes, and their mutations result in hamartomas in humans, which are characterized by multiple benign tumors in a variety of organs (Kwiatkowski 2003b). TSC1 stabilizes the TSC1-TSC2 complex, whereas TSC2 exerts GTPase activity to negatively regulate Rheb, a small GTP-binding protein, which activates mTORC1 (Gao et al. 2002; Inoki et al. 2003a; Kwiatkowski 2003a) (Fig. 1). Recently, additional upstream regulators of $m$ TOR have been identified. For example, it has been shown that hypoxia can be transduced to mTORC1 via REDD1 and REDD2 (Brugarolas et al. 2004). In response to hypoxia, HIF-1 induces the expression of REDD, which activates mTORC1 through TSC1-TSC2. In addition, the hVPS34 lipid kinase, a class III PI3K, can signal the availability of amino acids to mTORC1 independently of TSC2 and Rheb (Byfield et al. 2005).

The 4EBP1 protein (eIF4E binding protein) and the $\mathrm{S} 6 \mathrm{~K}$ ( $\mathrm{p} 70$ ribosomal protein S6 kinase) are two major substrates of mTORC1 (Fingar and Blenis 2004; Inoki et al. 2005; Wullschleger et al. 2006). Under basal conditions, S6K and 4EBP1 are bound to eIF3 (eukaryotic initiation factor 3) and remain inactive. On stimulation of growth signals, mTORC1 binds to eIF3 and phosphorylates S6K and 4EBP1 (Holz et al. 2005; Holz and Blenis 2005). Phosphorylation and activation of S6K by mTORC1 enhances the translation of mRNAs involved in ribosomal biogenesis, mitochondrial biogenesis, as well as oxygen delivery and consumption through phosphorylating substrates of S6K, including S6, a ribosomal protein (Hannan et al. 2003; Pende et al. 2004; Holz et al. 2005). At the same time, the phosphorylation of $4 \mathrm{EBP} 1$ by mTORC1 releases eIF4E (the eukaryotic initiation factor $4 \mathrm{E}$ ), which is essential for cap-dependent initiation of translation and promoting growth of the cell. As a net result, activated mTORC1 enhances cell growth by promoting protein translation and increasing cell mass (Fingar et al. 2002; Inoki et al. 2003b; Fingar et al. 2004). p53 Regulation of the IGF-1/AKT/mTOR Pathways

In addition to the regulation of $4 \mathrm{EBP} 1$ and S6K, mTORC1 regulates another important biological process, autophagy. Autophagy is the sequestration and subsequent digestion of cytoplasmic components, allowing for the adaptation of cells to stressful conditions, as well as the removal of damaged, potentially harmful cytoplasmic organelles, including defective mitochondria (Lum et al. 2005; Jin and White 2008). Autophagy can be activated through the inactivation of mTOR pathway. It has been shown that the activation of Akt and PI3K inhibits autophagy, whereas the inactivation of PTEN, LKB1, TSC1, or TSC2 all result in the inhibition of autophagy (Levine and Kroemer 2008; Mizushima et al. 2008). Autophagy accomplishes two important survival functions. First, autophagy provides nutrients from protein, lipid, and carbohydrate turnover, for cells through a catabolic breakdown of cellular components under the condition of nutrient starvation. Thus, mTOR mediates a switch between efficient translation of mRNAs that promotes energy production in the presence of glucose and catabolic degradation of existing organelles for the maintenance of cells in the absence of nutrients. Second, autophagy has an essential role in the maintenance of genomic stability (Levine and Kroemer 2008; Mizushima et al. 2008). For example, autophagy is also a normal cellular process to destroy defective mitochondria that are uncoupled and produce reactive oxygen species (ROS) so as to reduce the levels of ROS and decrease oxidative stress-induced damage and DNA mutations in cells (Shintani and Klionsky 2004). It has been shown that loss of one allele of either of the two haploinsufficient autophagy genes Beclin 1 or UVRAG, a Beclin 1binding protein, is sufficient to promote carcinogenesis (Yue et al. 2003; Liang et al. 2006). Therefore, autophagy is both a survival and a fidelity mechanism in cells.

Recent studies show that in addition to autophagy, the mTOR pathway also regulates the ubiquitination, internalization, and turnover of specific nutrient transporters. For example, mTORC1 regulates trafficking of nutrient transporters and promotes uptake of nutrients such as glucose, amino acids, lipoprotein, and iron 
Z. Feng

(Edinger and Thompson 2002; Schmelzle et al. 2004). Therefore, mTOR has also been suggested to be a regulator of membrane trafficking in cells.

\section{THE IGF-1/AKT PATHWAY}

In response to high levels of nutrients such as glucose, insulin is secreted, which results in the production of the IGF-1 and the uptake of glucose by cells via specific transporters. The binding of IGF-1 to its tyrosine kinase receptor (IGF-1R) results in the recruitment of the PI3 kinase (PI3K) to the plasma membrane and its activation, which in turn phosphorylates the phosphoinositides, increasing the concentration of PIP3 at the plasma membrane. PIP-3 is a small molecular weight ligand that activates lipid protein kinases, including PDK1 (3-phosphoinositide-dependent protein kinase 1) (Belham et al. 1999; Toker and Newton 2000). Therefore, increased PIP3 in turn activates PDK1 and AKT at the plasma membrane and results in the phosphorylation of AKT on Thr308 by PDK1. At the same time, mTORC2 (which is also called PDK2) phosphorylates AKT on Ser473 (Biondi et al. 2001; Scheid et al. 2002; Bayascas and Alessi 2005; Sarbassov et al. 2005b). The phosphorylation of AKT by both PDK1 and mTORC2 leads to the full activation of AKT. Although the upstream regulation of mTORC2 remains unclear, mTORC2 has been placed downstream of PI3K signaling because AKT Ser473 phosphorylation by mTORC2 can be stimulated by growth factors and inhibited by PI3K inhibitor, wortmannin (Sarbassov et al. 2005b). AKT has several antiapoptotic substrates in cells, including BAD and MDM2. AKT phosphorylation results in the inactivation of BAD, a proapoptotic protein, and activation of MDM2, respectively, which both lead to the inhibition of apoptosis (Datta et al. 1997; Zhou et al. 2001). Furthermore, AKT translocates from the plasma membrane to the nucleus, where it phosphorylates FOXO transcription factors (Brunet et al. 1999; Cully et al. 2006). The phosphorylated FOXO proteins then leave the nucleus, which results in a transcriptional program that enhances oxidative phosphorylation for efficient energy production, increases the levels of protein folding chaperones, heat shock proteins, and produces antioxidant proteins that decrease the levels of ROS. The removal of FOXO from the nucleus also turns off the production of p27, a tumor suppressor protein that inhibits cyclin D-cdk- $4 / 6$ protein kinases required for entry into the cell cycle by phosphorylating the $\mathrm{Rb}$ protein and liberating E2F-1 transcription factor required to enter the cell cycle. Thus, the removal of FOXO from the nucleus reduces the signaling forcellular apoptosis, and drives cells into cell cycle.

The mTOR pathway is coregulated by IGF-1/ AKT pathway to ensure both a reasonable level of nutrients and a positive signal for cell growth and division. AKT phosphorylates TSC2 on multiple sites and inhibits the TSC2 GTPase activity, which in turn activates Rheb and mTORC1 (Inoki et al. 2002; Potter et al. 2002). This coordination of IGF-1/AKT and mTOR pathways enables the activation of mTOR, which in turn promotes cell growth in response to the stimulation of growth factors, including insulin and IGF-1. Thus, mTOR regulates a translational control over cell growth, division, and energy metabolism, whereas IGF-1/AKT regulates the transcriptional control over similar functions that promote cell growth and division and inhibit apoptosis.

\section{p53 REGULATION OF THE IGF-1/AKT/ mTOR PATHWAYS}

The p53 pathway senses various intrinsic and extrinsic stress signals, including DNA damage, hypoxia, heat/cold shock, nutrition starvation, and oncogene activation (Vogelstein et al. 2000; Levine et al. 2006b; Vousden and Prives 2009). These stress signals can all reduce the fidelity of cell growth and division and subject cells to high error rates. In response to these stress signals, p53 selectively regulates the transcription of a set of its target genes, which initiates cell-cycle arrest, DNA repair, senescence, or apoptosis to maintain genomic stability, depending on cell type, environmental context, and/or degree of stress. Recent studies revealed that $\mathrm{p} 53$ pathway monitors the IGF-1/AKT and mTOR pathways; in response to stress, the p53 
pathway negatively regulates the IGF-1/AKT and mTOR pathways to shut down cell growth and division to avoid the introduction of infidelity into the process of cell growth and division (Feng et al. 2005; Levine et al. 2006a; Feng et al. 2007; Budanov and Karin 2008).

The $\mathrm{p} 53$ protein induces the expression of a group of p53 target genes in the IGF-1/AKT and mTOR pathways and all of these gene products negatively regulate the IGF-1/AKT and mTOR pathways in response to stress signals (Fig. 1). They are IGF-BP3, PTEN, TSC2, AMPK $\beta 1$, Sestrin1, and Sestrin2 (Buckbinder et al. 1995; Stambolic et al. 2001; Feng et al. 2005; Levine et al. 2006a; Feng et al. 2007; Budanov and Karin 2008). IGF-BP3 protein binds to free IGF-1 and prevents it from binding to the IGF-1 receptors to shut down IGF-1/AKT signaling. As a PIP3 phosphatase, PTEN degrades PIP3 to PIP2 and diminishes the function of PIP3 in the activation of PDK-1 and mTORC2. This in turn leads to the inactivation or decreased activation of AKT. The loss of the AKT activity increases the TSC1-TSC2 activity, which in turn decreases the mTORC1 activity. AMPK is a heterotrimeric protein in which the $\alpha$ subunit is the kinase catalytic subunit, the $\gamma$ subunit is the AMP binding subunit, and the $\beta$ subunit functions as a scaffold for the binding of $\alpha$ and $\gamma$ subunits (Hardie 2003; Hardie 2005). p53 activation increases the concentrations of the AMPK $\beta 1$, which in turn will increase the activity of AMPK and the activity of the TSC1-TSC2 complex and lead to the shutdown of mTOR pathway (Feng et al. 2007). p53 also directly up-regulates TSC2 concentrations, which has the same negative impact on the mTOR activity (Feng et al. 2005; Feng et al. 2007). Furthermore, p53 up-regulates the expression of Sestrin 1 and Sestrin 2, both of which activate AMPKand TSC2 to inhibit mTORC1 activity (Budanov and Karin 2008). Thus, through the regulation of these critical negative regulators in these two pathways, p53 shuts down IGF-1/ AKT and mTOR pathways, which are critical for cell growth and division, nutritional sensing, and metabolic regulation in the event of stress (Fig. 1).

The p53 activation enhances autophagy in cells. It has been shown that p53 activation in p53 Regulation of the IGF-1/AKT/mTOR Pathways

response to stress induces much more autophagosomes in p53 wild-type MEF (mouse embryo fibroblast) cells than p53 null MEF cells (Feng et al. 2005). This occurs through the inhibition of mTOR pathway by $\mathrm{p} 53$, and/or through the regulation of some p53 target genes directly involved in autophagy. p53 has been shown to regulate autophagy directly through its transcription regulation of DRAM (damage-regulated autophagy modulator) (Crighton et al. 2006), which is a lysosomal protein with six membrane-spanning regions. Overexpression of DRAM leads to the accumulation of autophagosomes in cells, whereas knockdown of DRAM prevents the p53-mediated accretion of autophagosomes. Interestingly, recently, it has been shown that the mutant $\mathrm{p} 53$ protein accumulated in cytoplasm of tumor cells can inhibit autophagy (Morselli et al. 2008). Although the mechanism by which mutant cytoplasmic p53 protein inhibits autophagy remains unclear, it supports the conception that the activation of autophagy by p 53 contributes to p53's function in tumor suppression.

The balance between a response to cellular stress or a commitment to cell growth and division is modulated by several regulatory loops between $\mathrm{p} 53$ and the IGF-1/AKT/mTOR pathways. mTORC1 phosphorylates and activates the $\alpha-4$ subunit of the PP2A phosphatase, which then dephosphorylates p53 on Ser 15 (removing an activating event for p53) (Kong et al. 2004). On the other hand, AMPK can directly or indirectly phosphorylate p53 on Ser15 in response to nutrient starvation (Imamura et al. 2001; Feng et al. 2005; Jones et al. 2005). Thus, mTORC1 and AMPK can coordinately regulate p53 in response to nutrient signals. Under the condition of nutrient deprivation (e.g., glucose starvation), the phosphorylation of p53 on Ser15 through AMPK leads to cellcycle arrest in normal MEF cells (Jones et al. 2005), whereas the same nutrient deprivation leads to the p53-mediated cell apoptosis in oncogene (E1A) transformed MEF cells (Feng et al. 2007). It is known that the E1A protein binds to the $\mathrm{Rb}$ protein, which frees the E2F-1 transcription factor. E2F-1 transcribes the p14 ARF, which binds to MDM2 and inhibits its 
Z. Feng

activity, which leads to the p53 activation. This is a classical $\mathrm{p} 53$ positive feedback loop between loss of $\mathrm{Rb}$ function and activation of $\mathrm{p} 53$, which senses the presence of activated oncogenes (E1A, myc, ras, $\beta$-catenin, etc.) in cells and informs the p53 pathway to focus on apoptosis as an outcome of nutrient stress (Harris and Levine 2005). PTEN connects another feedback loop between p53 and the IGF-1/AKT pathway. p53 activation leads to the up-regulation of PTEN (Stambolic et al. 2001; Feng et al. 2007), which in turn inhibits the activity of AKT (Cully et al. 2006; Levine et al. 2006a). The AKT can phosphorylate MDM2 on ser166/186, which activates MDM2 to decrease p53 levels and activity (Zhou et al. 2001; Ashcroft et al. 2002). This p53-PTEN-AKT-MDM2 loop positively regulates p53 activity after stress, and higher levels of p53 favor an apoptotic response. External factors acting on these loops in a positive or negative fashion will favor one response or the other. The places at which p53 chooses to shut down the mTOR and IGF-1-AKT pathways likely point to the rate-limiting steps or central nodes that have an impact on these networks. These interconnections help to elucidate the relationships between stress, longevity, and the control over metabolic networks and pathways involved in cancer and diabetes, both of which arise late in life.

\section{p53 REGULATION OF THE ENDOSOMAL COMPARTMENT}

Emerging evidence has revealed the regulation of endosomal compartment as a novel function of p53 to negatively regulate cell growth and division in response to stress (Yu et al. 2006; Lespagnol et al. 2008; Yu et al. 2009). The endosomal compartment is involved in a number of biological functions in cells, including internalizing membrane proteins to multivesicular bodies (MVBs) and lysosomes, producing exosomes, and generating autophagic vesicles.

Endosomes play an important role in the regulation of membrane receptor-mediated cell signaling (Polo and Di Fiore 2006; von Zastrow and Sorkin 2007; Sadowski et al. 2009). Endosomal vesicles internalize membrane receptors, which have engaged their ligands, and transports them to the intracellular compartments, including MVBs and lysosomes. During the transport, receptors may go through various modifications, including dephosphorylation, ubiquitination, or dissociation from ligands. These processes all contribute to attenuation of signals. Changes in the cellular location of receptors also affect the composition of attached signaling molecules. Finally, some of these receptors are degraded in MVBs and lysosomes, whereas others are trafficked back onto the cell surface via recycling endosomes. Thus, endocytic transport will either reduce the signals or set up new locations for cellular signaling. In this way, the kinetics of membrane receptor trafficking on ligand stimulation is maintained in a balance between degradative and recycling pathways to establish and retain homeostasis and to regulate receptor-mediated signaling in cells.

Exosome secretion is a nonclassical secretion pathway. In the classic secretion pathway, the protein passes through the endoplasmic reticulum/Golgi, and is incorporated into vesicles and secreted through exocytosis. As a nonclassical secretion pathway, exosome secretion goes through the MVBs of endosomes. In this pathway, intracellular vesicles are generated by inward budding from the limiting membrane into the lumen of endosomes and engulfing cytoplasmic components, and these vesicles are packaged into MVBs. The MVBs then fuse with the plasma membrane and release the intraluminal vesicles as exosomes into the extracellular space. Exosome vesicles can communicate with the immune system (dendritic cells) to immunize the host, fuse with adjacent cells to communicate physiological signals, or contribute to the extracellular matrix (Stoorvogel et al. 2002; Fevrier and Raposo 2004; Schorey and Bhatnagar 2008).

Recent studies have shown that p53 regulates the transcription of several genes involved in the regulation of functions of endosomal compartment, including TSAP6 Chmp4C, Caveolin-1, and DRAM (Yu et al. 2006; Lespagnol et al. 2008; Yu et al. 2009). TSAP6 is a multi-pass transmembrane protein, which can facilitate the secretion of proteins, such as the 
histamine-releasing factor (TCTP), via exosomes (Amzallag et al. 2004). Chmp4C is a cargo protein in the MVBs. MVBs contain about 30 proteins that are conserved from yeast to human. MVBs are composed of several sets of protein complexes, including ESCRT-III, which are sequentially recruited to the site of MVB formation and result in the progressive trafficking of vesicles in cells. Chmp4C is a charged MVB protein of the ESCRT-III protein complex (Saksena et al. 2007). Caveolin-1 belongs to the Caveolin protein family, consisting of three proteins, which serve as the structural component of plasma membrane vesicles, caveolae (Razani et al. 2002). Caveolae vesicles have been shown to be able to mediate the internalization of membrane proteins from the plasma membrane into cells, such as EGFR (the epidermal growth factor receptor) and TGF- $\beta$ (Di Guglielmo et al. 2003; Sigismund et al. 2005). Recent studies show that the EGFR and caveolin-1 proteins colocalize in the plasma membrane and the EGFR is then internalized at a faster rate after p53 activation, demonstrating that the p53 response decreases the availability of growth receptors at the cell surface to negatively regulate cell proliferation and division (Yu et al. 2009). Thus, p53 increases the functions of the endosome compartment; in response to stress signals, p53 regulates the transcription of TSAP6 and Chmp4C to enhance exosome production,

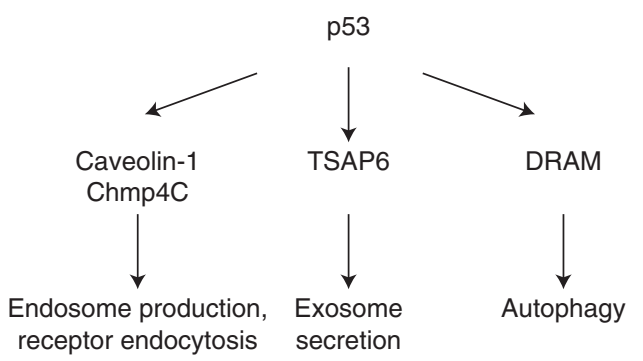

Figure 2. p53 regulation of the function of endosome compartment. In response to stress signals, p53 regulates the transcription of Chmp4C and Caveolin-1 to enhance endosome production and promote endosomal clearance of membrane receptors (e.g., EGFR) from cell surface, regulates the transcription of TSAP6 and Chmp4C to enhance exosome production, and regulates the transcription of DRAM to activate autophagy. p53 Regulation of the IGF-1/AKT/mTOR Pathways

regulates the transcription of DRAM to enhance autophagy, and regulates the transcription of Chmp4C and Caveolin-1 to enhance endosome production and promote endosomal clearance of membrane receptors (e.g., EGFR) from the plasma membrane (Fig. 2). In this fashion, the p53 protein helps to down-modulate cell growth and division after stress, and uses cellular reserves to maintain cells. Furthermore, these events communicate a cellular stress event to the immune system, adjacent cells, and the extracellular matrix. This also means that a localized p53 response in the body can have systemic con-sequences.

\section{SUMMARY}

The p53 pathway, the IGF-1-AKT pathway, and the TOR pathway are involved in sensing and integrating signals arising from nutrients and growth factors, and intrinsic and extrinsic stress signals. In turn, these pathways lead to cellular responses including the p53 transcriptional program and apoptosis, the forkhead transcriptional programs, autophagy, and translational controls, which determine cell growth or arrest, cell survival, or death. At the molecular level, these genes in these signal transduction pathways create a homeostatic mechanism that titrates the levels of nutrient availability and stress signals that can disrupt the fidelity of cell division. It is the management of this ratio that contributes to such processes as cancer, diabetes, efficient nutrient use, communication with reproductive organs, and longevity. As the "guardian of the genome," p53 responds to a wide variety of stress signals, which will decrease the fidelity of cell growth and division, and initiate cellular responses, including cellcycle arrest, DNA repair, apoptosis, or senescence to maintain genomic stability. At the same time, p53 selectively transcribes a set of target genes to negatively regulate the IGF-1/ AKT- 1 and mTOR pathways, and enhances endosomal compartment activities, including promoting autophagy, the production of exosome, and removal of membrane receptors from the cell surface. These activities all function to slow down cell growth and division, 
Z. Feng

conserve and reuse cellular resources, and notify other cells and organ systems (via the immune response) about the stresses. These functions are also an important part of cell and tissue repair after cell damage, virus infection, or hypoxia. This extensive communication and coordination between p53 and IGF-1/AKT/ mTOR pathways and endosomal compartment integrates these stress responses at the molecular, cellular, and systemic levels so as to limit the error frequency of cell growth and division during a stressful time.

\section{REFERENCES}

Amzallag N, Passer BJ, Allanic D, Segura E, Thery C, Goud B, Amson R, Telerman A. 2004. TSAP6 facilitates the secretion of translationally controlled tumor protein/ histamine-releasing factor via a nonclassical pathway. J Biol Chem 279: 46104-46112.

Ashcroft M, Ludwig RL, Woods DB, Copeland TD, Weber HO, MacRae EJ, Vousden KH. 2002. Phosphorylation of HDM2 by Akt. Oncogene 21: 1955-1962.

Bayascas JR, Alessi DR. 2005. Regulation of Akt/PKB Ser473 phosphorylation. Mol Cell 18: 143-145.

Belham C, Wu S, Avruch J. 1999. Intracellular signalling: PDK1 - a kinase at the hub of things. Curr Biol 9: R93-96.

Biondi RM, Kieloch A, Currie RA, Deak M, Alessi DR. 2001. The PIF-binding pocket in PDK1 is essential for activation of S6K and SGK, but not PKB. EMBO J 20: $4380-4390$.

Brugarolas J, Lei K, Hurley RL, Manning BD, Reiling JH, Hafen E, Witters LA, Ellisen LW, Kaelin WG Jr, 2004. Regulation of mTOR function in response to hypoxia by REDD1 and the TSC1/TSC2 tumor suppressor complex. Genes Dev 18: 2893-2904.

Brunet A, Bonni A, Zigmond MJ, Lin MZ, Juo P, Hu LS, Anderson MJ, Arden KC, Blenis J, Greenberg ME. 1999. Akt promotes cell survival by phosphorylating and inhibiting a Forkhead transcription factor. Cell 96: 857-868.

Buckbinder L, Talbott R, Velasco-Miguel S, Takenaka I, Faha B, Seizinger BR, Kley N. 1995. Induction of the growth inhibitor IGF-binding protein 3 by p53. Nature 377: 646-649.

Budanov AV, Karin M. 2008. p53 target genes sestrin1 and sestrin 2 connect genotoxic stress and mTOR signaling. Cell 134: 451-460.

Byfield MP, Murray JT, Backer JM. 2005. hVps34 is a nutrient-regulated lipid kinase required for activation of p70 S6 kinase. J Biol Chem 280: 33076-33082.

Crighton D, Wilkinson S, O'Prey J, Syed N, Smith P, Harrison PR, Gasco M, Garrone O, Crook T, Ryan KM. 2006. DRAM, a p53-induced modulator of autophagy, is critical for apoptosis. Cell 126: 121-134.

Cully M, You H, Levine AJ, Mak TW. 2006. Beyond PTEN mutations: The PI3K pathway as an integrator of multi- ple inputs during tumorigenesis. Nat Rev Cancer 6: 184-192.

Datta SR, Dudek H, Tao X, Masters S, Fu H, Gotoh Y, Greenberg ME. 1997. Akt phosphorylation of BAD couples survival signals to the cell-intrinsic death machinery. Cell 91 : 231-241.

Di Guglielmo GM, Le Roy C, Goodfellow AF, Wrana JL. 2003. Distinct endocytic pathways regulate TGF- $\beta$ receptor signalling and turnover. Nat Cell Biol 5: 410-421.

Edinger AL, Thompson CB. 2002. Akt maintains cell size and survival by increasing mTOR-dependent nutrient uptake. Mol Biol Cell 13: 2276-2288.

Feng Z, Hu W, de Stanchina E, Teresky A, Jin S, Lowe S, Levine AJ. 2007. The regulation of AMPK $\beta 1$, TSC2, and PTEN expression by p53: Stress, cell and tissue specificity, and the role of these gene products in modulating the IGF-1-AKT-mTOR pathways. Cancer Res 67: 3043-3053.

Feng Z, Zhang H, Levine AJ, Jin S. 2005. The coordinate regulation of the $\mathrm{p} 53$ and mTOR pathways in cells. Proc Natl Acad Sci 102: 8204-8209.

Fevrier B, Raposo G. 2004. Exosomes: Endosomal-derived vesicles shipping extracellular messages. Curr Opin Cell Biol 16: 415-421.

Fingar DC, Blenis J. 2004. Target of rapamycin (TOR): An integrator of nutrient and growth factor signals and coordinator of cell growth and cell cycle progression. Oncogene 23: 3151-3171.

Fingar DC, Richardson CJ, Tee AR, Cheatham L, Tsou C, Blenis J. 2004. mTOR controls cell cycle progression through its cell growth effectors S6K1 and 4E-BP1/eukaryotic translation initiation factor 4E. Mol Cell Biol 24: $200-216$.

Fingar DC, Salama S, Tsou C, Harlow E, Blenis J. 2002. Mammalian cell size is controlled by mTOR and its downstream targets S6K1 and 4EBP1/eIF4E. Genes Dev 16: $1472-1487$.

Gao X, Zhang Y, Arrazola P, Hino O, Kobayashi T, Yeung RS, $\mathrm{Ru}$ B, Pan D. 2002. Tsc tumour suppressor proteins antagonize amino-acid-TOR signalling. Nat Cell Biol 4: 699-704.

Hannan KM, Brandenburger Y, Jenkins A, Sharkey K, Cavanaugh A, Rothblum L, Moss T, Poortinga G, McArthur GA, Pearson RB, et al. 2003. mTOR-dependent regulation of ribosomal gene transcription requires $\mathrm{S} 6 \mathrm{~K} 1$ and is mediated by phosphorylation of the carboxy-terminal activation domain of the nucleolar transcription factor UBF. Mol Cell Biol 23: 8862-8877.

Hara K, Maruki Y, Long X, Yoshino K, Oshiro N, Hidayat S, Tokunaga C, Avruch J, Yonezawa K. 2002. Raptor, a binding partner of target of rapamycin (TOR), mediates TOR action. Cell 110: 177-189.

Hardie DG. 2003. Minireview: The AMP-activated protein kinase cascade: The key sensor of cellular energy status. Endocrinology 144: 5179-5183.

Hardie DG. 2005. New roles for the LKB1- > AMPK pathway. Curr Opin Cell Biol 17: 167-173.

Harris SL, Levine AJ. 2005. The p53 pathway: Positive and negative feedback loops. Oncogene 24: 2899-2908.

Hay N, Sonenberg N. 2004. Upstream and downstream of mTOR. Genes Dev 18: 1926-1945. 
Holz MK, Blenis J. 2005. Identification of S6 kinase 1 as a novel mammalian target of rapamycin (mTOR)-phosphorylating kinase. J Biol Chem 280: 26089-26093.

Holz MK, Ballif BA, Gygi SP, Blenis J. 2005. mTOR and S6K1 mediate assembly of the translation preinitiation complex through dynamic protein interchange and ordered phosphorylation events. Cell 123: 569-580.

Imamura K, Ogura T, Kishimoto A, Kaminishi M, Esumi H. 2001. Cell cycle regulation via p53 phosphorylation by a $5^{\prime}$-AMP activated protein kinase activator, 5-aminoimidazole-4-carboxamide-1- $\beta$-D-ribofuranoside, in a human hepatocellular carcinoma cell line. Biochem Biophys Res Commun 287: 562-567.

Inoki K, Corradetti MN, Guan KL. 2005. Dysregulation of the TSC-mTOR pathway in human disease. Nat Genet 37: 19-24.

Inoki K, Li Y, Xu T, Guan KL. 2003a. Rheb GTPase is a direct target of TSC2 GAP activity and regulates mTOR signaling. Genes Dev 17: 1829-1834.

Inoki K, Zhu T, Guan KL. 2003b. TSC2 mediates cellular energy response to control cell growth and survival. Cell 115: $577-590$.

Inoki K, Li Y, Zhu T, Wu J, Guan KL. 2002. TSC2 is phosphorylated and inhibited by Akt and suppresses mTOR signalling. Nat Cell Biol 4: 648-657.

Jacinto E, Facchinetti V, Liu D, Soto N, Wei S, Jung SY, Huang Q, Qin J, Su B. 2006. SIN1/MIP1 maintains rictor-mTOR complex integrity and regulates Akt phosphorylation and substrate specificity. Cell 127: 125-137.

Jacinto E, Loewith R, Schmidt A, Lin S, Ruegg MA, Hall A, Hall MN. 2004. Mammalian TOR complex 2 controls the actin cytoskeleton and is rapamycin insensitive. Nat Cell Biol 6: 1122-1128.

Jin S, White E. 2008. Tumor suppression by autophagy through the management of metabolic stress. Autophagy 4: 563-566.

Jones RG, Plas DR, Kubek S, Buzzai M, Mu J, Xu Y, Birnbaum MJ, Thompson CB. 2005. AMP-activated protein kinase induces a p53-dependent metabolic checkpoint. Mol Cell 18: 283-293.

Kim DH, Sarbassov DD, Ali SM, King JE, Latek RR, Erdjument-Bromage H, Tempst P, Sabatini DM. 2002. mTOR interacts with raptor to form a nutrient-sensitive complex that signals to the cell growth machinery. Cell 110: $163-175$.

Kim DH, Sarbassov DD, Ali SM, Latek RR, Guntur KV, Erdjument-Bromage H, Tempst P, Sabatini DM. 2003. $\mathrm{G} \beta \mathrm{L}$, a positive regulator of the rapamycin-sensitive pathway required for the nutrient-sensitive interaction between raptor and mTOR. Mol Cell 11: 895-904.

Kong M, Fox CJ, Mu J, Solt L, Xu A, Cinalli RM, Birnbaum MJ, Lindsten T, Thompson CB. 2004. The PP2Aassociated protein $\alpha 4$ is an essential inhibitor of apoptosis. Science 306: 695-698.

Kwiatkowski DJ. 2003a. Rhebbing up mTOR: New insights on TSC1 and TSC2, and the pathogenesis of tuberous sclerosis. Cancer Biol Ther 2: 471-476.

Kwiatkowski DJ. 2003b. Tuberous sclerosis: From tubers to mTOR. Ann Hum Genet 67: 87-96.

Lespagnol A, Duflaut D, Beekman C, Blanc L, Fiucci G, Marine JC, Vidal M, Amson R, Telerman A. 2008. Exosome secre- p53 Regulation of the IGF-1/AKT/mTOR Pathways

tion, including the DNA damage-induced p53-dependent secretory pathway, is severely compromised in TSAP6/ Steap3-null mice. Cell Death Differ 15: 1723-1733.

Levine B, Kroemer G. 2008. Autophagy in the pathogenesis of disease. Cell 132: 27-42.

Levine AJ, Hu W, Feng Z. 2006b. The P53 pathway: What questions remain to be explored? Cell Death Differ 13: 1027-1036.

Levine AJ, Feng Z, Mak TW, You H, Jin S. 2006a. Coordination and communication between the p53 and IGF-1-AKT-TOR signal transduction pathways. Genes Dev 20: $267-275$.

Liang C, Feng P, Ku B, Dotan I, Canaani D, Oh BH, Jung JU. 2006. Autophagic and tumour suppressor activity of a novel Beclin1-binding protein UVRAG. Nat Cell Biol 8: 688-699.

Lum JJ, Bauer DE, Kong M, Harris MH, Li C, Lindsten T, Thompson CB. 2005. Growth factor regulation of autophagy and cell survival in the absence of apoptosis. Cell 120: 237-248.

Mizushima N, Levine B, Cuervo AM, Klionsky DJ. 2008. Autophagy fights disease through cellular self-digestion. Nature 451: 1069-1075.

Morselli E, Tasdemir E, Maiuri MC, Galluzzi L, Kepp O, Criollo A, Vicencio JM, Soussi T, Kroemer G. 2008. Mutant p53 protein localized in the cytoplasm inhibits autophagy. Cell Cycle 7: 3056-3061.

Pende M, Um SH, Mieulet V, Sticker M, Goss VL, Mestan J, Mueller M, Fumagalli S, Kozma SC, Thomas G. 2004. S6K1 $(-/-) / \mathrm{S} 6 \mathrm{~K} 2(-/-)$ mice exhibit perinatal lethality and rapamycin-sensitive $5^{\prime}$-terminal oligopyrimidine mRNA translation and reveal a mitogen-activated protein kinase-dependent S6 kinase pathway. Mol Cell Biol 24: 3112-3124.

Polo S, Di Fiore PP. 2006. Endocytosis conducts the cell signaling orchestra. Cell 124: 897-900.

Potter C, Pedraza L, Xu T. 2002. Akt regulates growth by directly phosphorylating Tsc2. Nat Cell Biol 4: 658-665.

Razani B, Woodman SE, Lisanti MP. 2002. Caveolae: From cell biology to animal physiology. Pharmacol Rev 54: 431-467.

Sadowski L, Pilecka I, Miaczynska M. 2009. Signaling from endosomes: Location makes a difference. Exp Cell Res 315: $1601-1609$.

Saksena S, Sun J, Chu T, Emr SD. 2007. ESCRTing proteins in the endocytic pathway. Trends Biochem Sci 32: 561-573.

Sarbassov DD, Ali SM, Kim DH, Guertin DA, Latek RR Erdjument-Bromage H, Tempst P, Sabatini DM. 2004. Rictor, a novel binding partner of mTOR, defines a rapamycin-insensitive and raptor-independent pathway that regulates the cytoskeleton. Curr Biol 14: 1296-1302.

Sarbassov DD, Ali SM, Sabatini DM. 2005a. Growing roles for the mTOR pathway. Curr Opin Cell Biol 17: 596-603.

Sarbassov DD, Guertin DA, Ali SM, Sabatini DM. 2005b. Phosphorylation and regulation of Akt/PKB by the rictor-mTOR complex. Science 307: 1098-1101.

Scheid MP, Marignani PA, Woodgett JR. 2002. Multiple phosphoinositide 3-kinase-dependent steps in activation of protein kinase B. Mol Cell Biol 22: 6247-6260.

Schmelzle T, Beck T, Martin DE, Hall MN. 2004. Activation of the RAS/cyclic AMP pathway suppresses a TOR deficiency in yeast. Mol Cell Biol 24: 338-351. 
Z. Feng

Schorey JS, Bhatnagar S. 2008. Exosome function: From tumor immunology to pathogen biology. Traffic 9: 871-881.

Shaw RJ, Bardeesy N, Manning BD, Lopez L, Kosmatka M, DePinho RA, Cantley LC. 2004b. The LKB1 tumor suppressor negatively regulates $\mathrm{mTOR}$ signaling. Cancer Cell 6: 91-99.

Shaw R, Kosmatka M, Bardeesy N, Hurley R, Witters L, DePinho R, Cantley L. 2004a. The tumor suppressor LKB1 kinase directly activates AMP-activated kinase and regulates apoptosis in response to energy stress. Proc Natl Acad Sci 101: 3329-3335.

Shintani T, Klionsky DJ. 2004. Autophagy in health and disease: A double-edged sword. Science 306: 990-995.

Sigismund S, Woelk T, Puri C, Maspero E, Tacchetti C, Transidico P, Di Fiore PP, Polo S. 2005. Clathrinindependent endocytosis of ubiquitinated cargos. Proc Natl Acad Sci 102: 2760-2765.

Stambolic V, MacPherson D, Sas D, Lin Y, Snow B, Jang Y, Benchimol S, Mak TW. 2001. Regulation of PTEN transcription by p53. Mol Cell 8: 317-325.

Stoorvogel W, Kleijmeer MJ, Geuze HJ, Raposo G. 2002. The biogenesis and functions of exosomes. Traffic 3: 321-330.

Toker A, Newton AC. 2000. Cellular signaling: Pivoting around PDK-1. Cell 103: 185-188.
Vogelstein B, Lane D, Levine AJ. 2000. Surfing the p53 network. Nature 408: 307-310.

von Zastrow M, Sorkin A. 2007. Signaling on the endocytic pathway. Curr Opin Cell Biol 19: 436-445.

Vousden KH, Prives C. 2009. Blinded by the light: The growing complexity of p53. Cell 137: 413-431.

Wullschleger S, Loewith R, Hall MN. 2006. TOR signaling in growth and metabolism. Cell 124: 471-484.

Yoo L, Chung D, Yuan J. 2002. LKB1-A master tumour suppressor of the small intestine and beyond. Nat Rev Cancer 2: 529-535.

Yu X, Harris SL, Levine AJ. 2006. The regulation of exosome secretion: A novel function of the p53 protein. Cancer Res 66: 4795-4801.

Yu X, Riley T, Levine AJ. 2009. The regulation of the endosomal compartment by p53 the tumor suppressor gene. FEBS J 276: 2201-2212.

Yue Z, Jin S, Yang C, Levine AJ, Heintz N. 2003. Beclin 1, an autophagy gene essential for early embryonic development, is a haploinsufficient tumor suppressor. Proc Natl Acad Sci 100: 15077-15082.

Zhou BP, Liao Y, Xia W, Zou Y, Spohn B, Hung MC. 2001. HER-2/neu induces p53 ubiquitination via Aktmediated MDM2 phosphorylation. Nat Cell Biol 3: 973-982. 


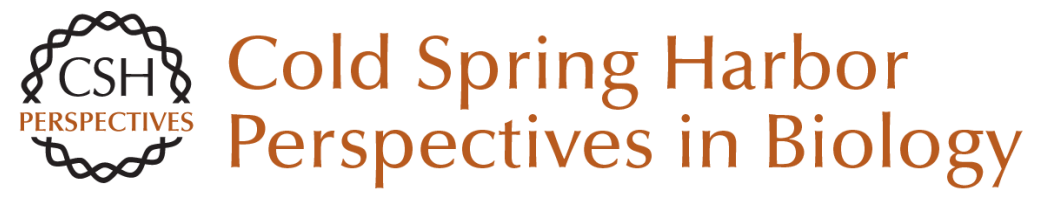

\section{p53 Regulation of the IGF-1/AKT/mTOR Pathways and the Endosomal Compartment}

\section{Zhaohui Feng}

Cold Spring Harb Perspect Biol 2010; doi: 10.1101/cshperspect.a001057 originally published online November 18, 2009

\section{Subject Collection The p53 Family}

The Origins and Evolution of the p53 Family of Genes

Vladimir A. Belyi, Prashanth Ak, Elke Markert, et al.

Mouse Models of p53 Functions

Guillermina Lozano

TP53 Mutations in Human Cancers: Origins, Consequences, and Clinical Use

Magali Olivier, Monica Hollstein and Pierre Hainaut

p53 Research: The Past Thirty Years and the Next Thirty Years

David Lane and Arnold Levine

Transcriptional Regulation by P53

Rachel Beckerman and Carol Prives

p53-based Cancer Therapy

David P. Lane, Chit Fang Cheok and Sonia Lain

Phylogeny and Function of the Invertebrate p53

Superfamily

Rachael Rutkowski, Kay Hofmann and Anton Gartner

Tied Up in Loops: Positive and Negative

Autoregulation of p53

Xin Lu
The Tumor Suppressor p53: From Structures to

Drug Discovery

Andreas C. Joerger and Alan R. Fersht

p53 Regulation of Metabolic Pathways

Eyal Gottlieb and Karen H. Vousden

The Regulation of the p53-mediated Stress

Response by MDM2 and MDM4

Mary Ellen Perry

Zebrafish Models of p53 Functions

Narie Y. Storer and Leonard I. Zon

p63 and p73, the Ancestors of p53

V. Dötsch, F. Bernassola, D. Coutandin, et al.

Pathologies Associated with the p53 Response Andrei V. Gudkov and Elena A. Komarova

Single-nucleotide Polymorphisms in the p53

Signaling Pathway Lukasz F. Grochola, Jorge Zeron-Medina, Sophie Mériaux, et al.

Clinical Outcomes and Correlates of TP53

Mutations and Cancer

Ana I. Robles and Curtis C. Harris

For additional articles in this collection, see http://cshperspectives.cshlp.org/cgi/collection/

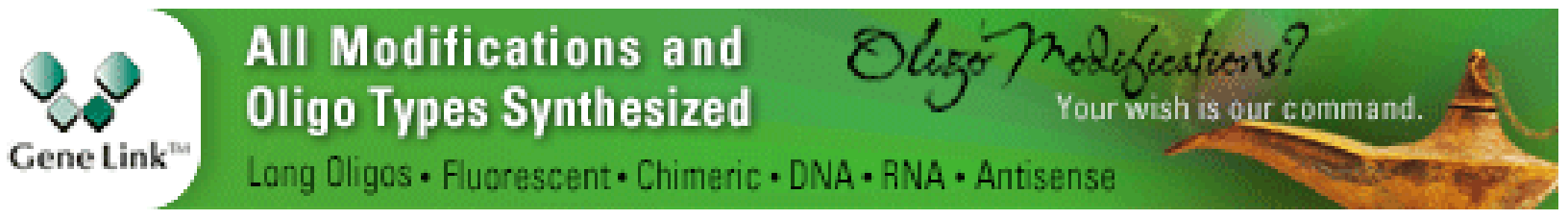

Copyright @ 2010 Cold Spring Harbor Laboratory Press; all rights reserved 